L'CRI-

JC-112339

PREPRIYT

\title{
Picosecond High Pressure Gas Switch Experiment
}

\author{
W. R. Cravey, E. K. Freytag, D. A. Goerz, \\ P. Poulsen, and P. A. Pincosy \\ Lawrence Livermore National Laboratory
}

This paper was prepared for submittal to:

Conference Proceedings of the 9th IEEE International Pulsed

Power Conference, Albuquerque, New Mexico

June 21-23, 1993

August 1993

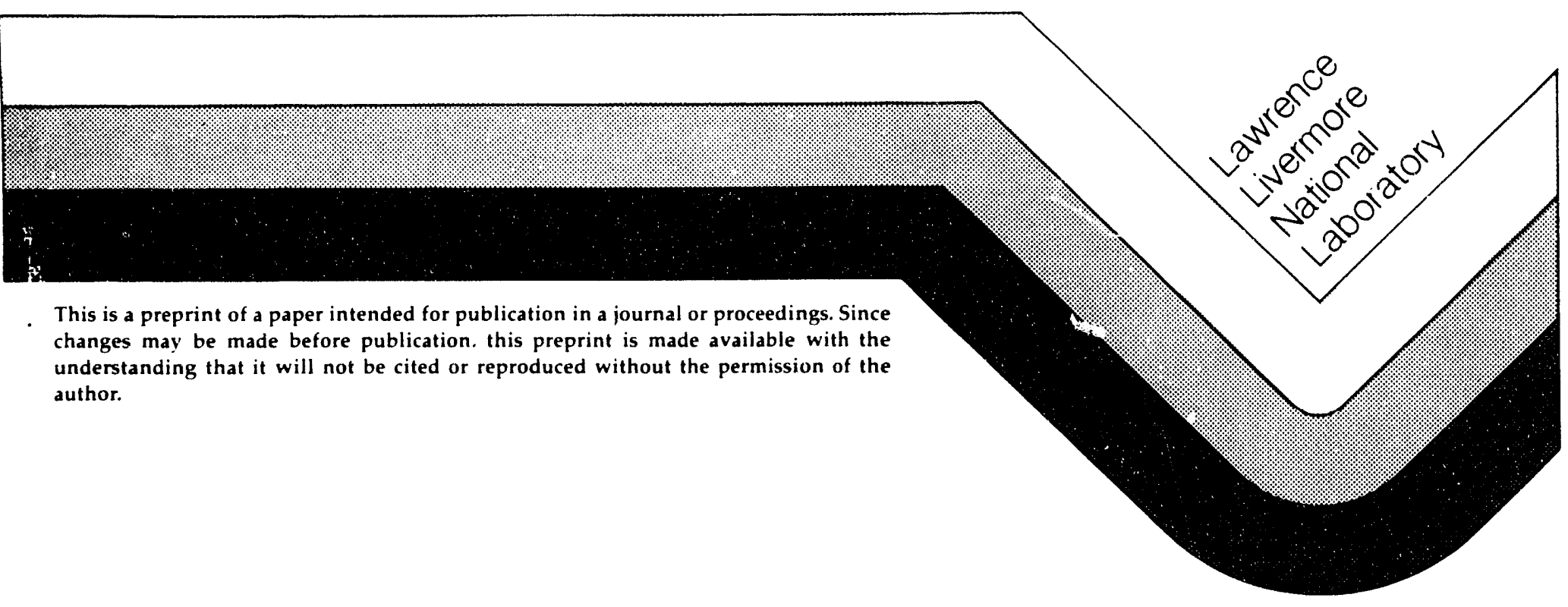

This is a preprint of a paper intended for publication in a journal or proceedings. Since changes may be made before publication. this preprint is made available with the understanding that it will not be cited or reproduced without the permission of the author. 


\section{DISCLAIMER}

This document was prepared as an account of work sponsored by an agency of the United States Government. Neither the United States Government nor the University of California nor any of their employees, makes any warranty, express or implied, or assumes any legal liability or responsibility for the accuracy, completeness, or usefulness of any information, apparatus, product, or process disclosed, or represents that its use would not infringe privately owned rights. Reference herein to any specific commercial products, process, or service by trade name, trademark, manufacturer, or otherwise, does not necessarily constitute or imply its endorsement, recommendation, or favoring by the United States Government or the University of California. The views and opinions of authors expressed herein do not necessarily state or reflect those of the United States Government or the University of California, and shall not be used for advertising or product endorsement purposes. 


\title{
Picosecond High Pressure Gas Switch Experiment*
}

\author{
W. R. Cravey, E. K. Freytag, D. A. Goerz, \\ P. Poulsen, and P. A. Pincosy \\ Lawrence Livermore National Laboratory \\ Livermore, CA 94550-9900
}

\section{Abstract}

A High Pressure Gas Switch has been developed and tested at LLNL. Risetimes on the order of 200 picoseconds have been observed at $1 \mathrm{kHz}$ prf and $\mathrm{l}$ atmosphere pressures. Calculations show that switching closure times on the order of tens of picoseconds can be achieved at higher pressures and electric fields. A voltage hold-off of $1 \mathrm{MV} / \mathrm{cm}$ has been measured at 10 atmospheres and several $\mathrm{MV} / \mathrm{cm}$ appears possible with the HPGS. With such high electric field levels, energy storage of tens of Joules in a reasonably sized package is achievable.

Initial HPGS performance has been characterized using the WASPl pulse generator at LLNL. A detailed description of the switch used for initial testing is given. Switch recovery times of $1-\mathrm{ms}$ have been measured at 1 atmosphere. Data on the switching uniformity, voltage hold-off recovery, and pulse repeatability, is presented. In addition, a physics switch model is described and results are compared with experimental data.

Modifications made to the WASP HV pulser in order to drive the HPGS will also be discussed. Recovery times of less than $1 \mathrm{~ms}$ were recorded without gas flow in the switch chambers. Low pressure synthetic air was used as the switch dielectric. Longer recovery times were required when it was necessary to over-voltage the switch.

\section{Introduction}

An ultrawide-band source requires a pulsed power modulator. a fast switch, and a radiating antenna. For broad-band radiation in the $\mathrm{GHz}$ range, the pulse energy must be released with a fast rising pulse (i.e., tens of picoseconds). Of the possible pulse sharpening methods in the sub-nanosecond time scale, a highpressure gas switch $2,3,4$ can produce short and high-voltage pulses at energies (joules) of interest resulting in high-power radiation. Although discharge physics are relatively well understood, certain switch issues remain to be determined.

Several areas of switch performance were measured which included, switching uniformity across the gap, switch recovery, and repeatability. A comparison of simple avalanche physics modeling of the pulse charging and gap voltage collapse to the

- experimentally measured results is discussed, along with the calculated pulse waveform for a much higher voltage and pressure switch. Also, a discussion of the modifications made on an existing pulse generator at LLNL so that it could be used as a test bed for the HPGS is given.

\section{Switch Operation}

Two configurations of the switch were tested: a $50-\Omega$ coaxial line and a $17-\Omega$ parallel-plate transmission line ${ }^{5}$. All of the measurements described in this paper were done with the parallel-plate line. An initial electron density, $n$, is produced in the gap by a UV source. The transmission line is charged by the pulsed power supply until the gap voltage collapses and the voltage pulse is propagated down the line. The end of the line was shorted. A description of the switch physics is given in earlier work 6 .

\section{Experimental Setup}

The geometry for the parallel plate transmission line is shown in Figure 1. This geometry was only operated at atmospheric pressure. To observe switch phasing, the p!ate transmission line shown in Figure 1 was used with a 2-min gap, $g$, across the $10-\mathrm{cm}$ width, $w$, of the line. The pulse charging supply stores energy in the $10 \mathrm{~cm}$ upstream of the gap until voltage collapse occurs, and then launches a pulse down the 20$\mathrm{cm}$ line to a shorted end. The plates were separated by $5 \mathrm{~mm}, \mathrm{~s}$, resulting in an impedance of $17 \Omega$. The voltages were monitored with four D-dot probes. Probe 1 is located $1.5 \mathrm{~cm}$ upstream of the gap centerline and probe 3 is $1.5 \mathrm{~cm}$ downstream along the transmission line center. Probes 2 and 4 were placed at $3 \mathrm{~cm}$ outboard of the downstream probe.

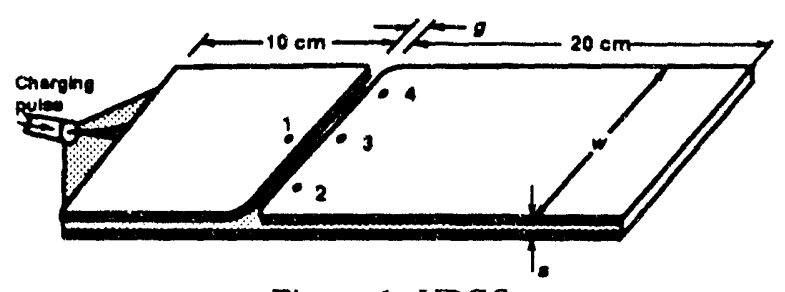

Figure 1. HPGS

To ensure some resident electron density in the gap as the charging pulse is applied, the gap is irradiated by $U^{7}$ from a spark source. The wide-band assist pulser WASP was used to pulse charge the plate transmission line at repetition rates from 1 $\mathrm{Hz}$ to $1 \mathrm{kHz}$ for 1 -second duration bursts. The output pulses were measured with a B-dot probe on the output line and the signal was recorded on a SCD5000, 4.5-GHz transient digitizer. The signals from the $\mathrm{D}$-dot probes were also recorded on the SCD5000 transient digitizers. Due to the high frequency of the D-dot signals, and the losses associated with the signal lines, the system frequency response of each signal line was measured using a picosecond pulser and then removed from the pulsed experimental measurements during the data reduction phase.

\section{Experimental Results}

For the parallel-plate transmission line in atmospheric pressure, the charging pulse developed a peak of $100 \mathrm{kV} / \mathrm{cm}$ across the gap as the voltage rose in $1.5 \mathrm{~ns}$. In the 50-W coaxial line air gap, pressurized to $10 \mathrm{~atm}$, an electric field of $1 \mathrm{MV} / \mathrm{cm}$ was obtained. At 1 atm of air press're, the gap voltage collapsed to half in $250 \mathrm{ps}$ both for the coaxial line and the plate transmission line. It follows that with several tens of atmospheres pressure the voltage collapse will occur in a few tens of picoseconds. 


\section{Switching Uniformity and Repeatability}

In order to launch a rapidly rising pulse that is uniform across the transmission line width, we have required that the switching gap be nearly the full width of the line.

We determined the relative arrival time at the two outboard probes ( 2 and 4 ). Without an ionizing spark, the signal arrived at probe 2 an average of 47 ps prior to arriving at probe 4 , and the standard deviation of the difference in arrival time was $126 \mathrm{ps,}$ considerably greater than the average difference in arrival time. Because the probes are located $6 \mathrm{~cm}$ apart, a variation of $126 \mathrm{ps}$ indicates a significant variation of location of the gap current, thus showing that it is not uniform along the length of the gap. When the UV ionizing spark was applied, the average arrival time difference to probes 2 and 4 was measured to be about 25 ps. The variation in this arrival time was 18 ps (11 shots)

- or a significant reduction from the 126 ps when no UV spark was used.

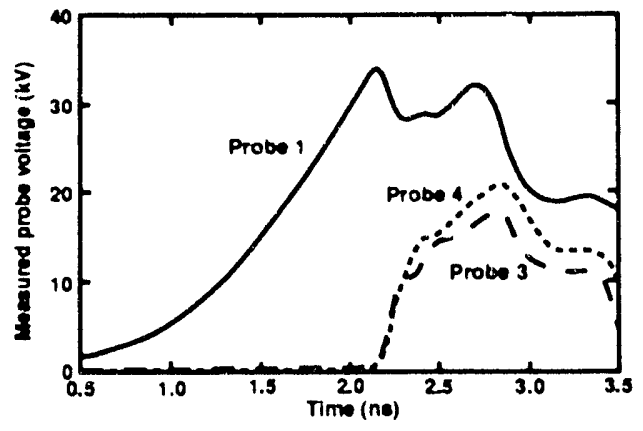

Figure 2. Charging and launched voltage pulses in the parallel-plate transmission line with atmospheric air.

The variation in arrival time between probes 2 and 3 was 20 ps or within the instrumental precision. We conclude that with a UV spark source, the gap discharge is uniform along its length to within the measurement accuracy. It was also observed that probes 2 and 4 were typically very similar in wave shape when the phasing was good, and different otherwise. The difference in the data from probes 2 and 4 was due to breakdown waves reflecting from the edge of the transmission line and adding to probes 2 and 4 differently than to probe 3 .

Repetition rate operation was tested up to $1 \mathrm{kHz}$. The WASP pulser provided a voltage pulse that was about two times

- higher on the first pulse due to the overvoltage of the output switch on the WASP. The UV spark source could not be repeated at this rep-pate. The issue was whether there were enough resident electrons from the previous breakdown to uniformly seed the gap with enough electrons for a phased breakdown. On a given burst, we recorded the first breakdown and every onehundredth breakdown that followed, up to three additional pulses as seen in Figure 3.

Unlike these three launched pulses, the wave shape should be almost identical if the gap breakdown is uniform across its length. For repeated breakdowns up to the $1-\mathrm{kHz}$ pulse repetition frequency (prf), the variation in pulse arrival time among probes 2, 3 and 4 was similar to that observed when no UV spark was produced. Fiducial corrections were crucial to making the measurements, and care was taken to determine the relative difference in trigger delays and signal delays between D-dots. For the first pulse in the train when the UV spark was produced, the relative timing among probes 2,3 and 4 was within measurement accuracy. In Figure 3, we observed that the repeated pulses reached the same voltage, $12 \mathrm{kV}$. The first pulse reaches an amplitude of $20 \mathrm{kV}$. The difference is because the WASP pulser produces a faster rising and higher voltage pulse on the first pulse, and all subsequent pulses are repeatable with slower rise times and lower amplitudes.

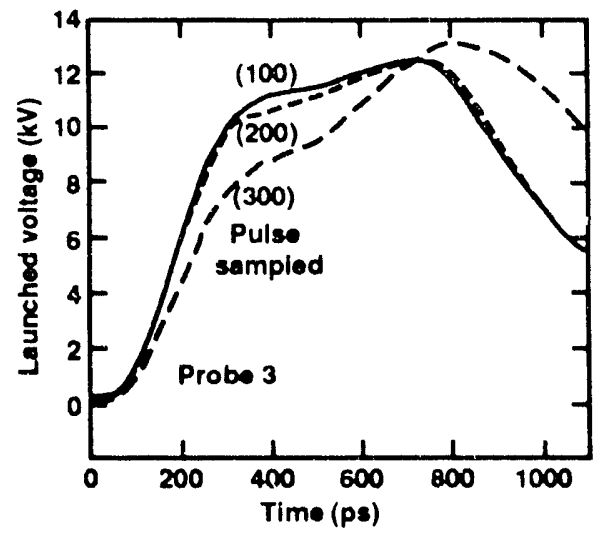

Figure 3. Launched voltage pulse samples at $1 \mathrm{kHz}$ prf with no UV spark.

\section{Voltage Recovery}

With prfs up to $1 \mathrm{kHz}$, the launched voltage pulses had a very low amplitude jitter. Pulse amplitude jitter was very low $<5$ $\%$ for the full second of the burst showing that switch recovery up to $1000 \mathrm{~Hz}$ was accomplished.

\section{Modeling}

When the gap electron density avalanche is modeled using the Townsend coefficierıt and the drift velocity, it becomes apparent that a difference of several orders of magnitude of initial electron density, $n$, makes a relatively small change in the formative time to voltage collapse. For example, with an $E / P$ of 50 across the gap, the time of collapse for a 2-ns charge time varied 33 ps per decade of initial electron density charge, going from $10^{3}$ to $10^{9}$ electrons $/ \mathrm{cm}^{3}$. The launched pulse wave rises in 125 ps. Initial electron density variations within a factor of 10 along the length of the gap should have a minor effect on the phase of the propagated wave. Stringent control of the gap electron density during the initial charging time is therefore not necessary.

In Figure 4, the modeled breakdown in the plate transmission line gap is compared to the measured pulses for air breakdown at $1 \mathrm{~atm}$ of pressure. The model assumes a ( $1-\cos x)$ charging pulse waveform, which is comparable to the measured charging pulse except for the low voltage foot. The breakdown electric field is closely predicted and can be correctly predicted for higher pressures. The launched pulse is closely predicted up to the time when the wave propagating back to the input line returns to the gap. The assumed input charging wave in the model does not match the real wave after this time and the model does not include the shorted end of the plate transmission line. Because the gap voltage rise is significantly above the static breakdown voltage, the launched pulse rise time is typically five times faster than the pulse charging time. To achieve pulses with picosecond rise times, a staged switch would be required. 


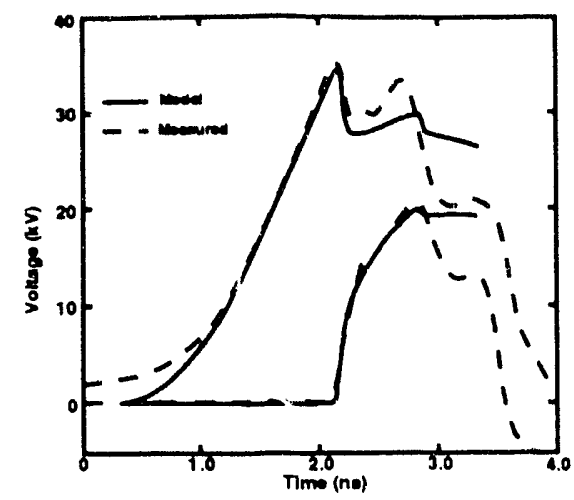

Figure 4. Comparing calculated and measured charging and launched voltage pulses.

The model was capable of using several gases, such as helium, nitrogen, argon, silane, and others. Calculations show that similar electric fields can be obtained bu: with varying required pressures. The differences lie in the vultage collapse rates, especially as $E / P$ falls to lower values where for some gases, electron attachment plays a role.

The electrical energy stored in the transmission line before switching is dependent on the field volume and the voltage. The $E / P$ scaling indicates that a pressure increase allows a proportionally higher electric field. In helium at $150 \mathrm{~atm}$, the launched pulse is calculated to be 200 ps long see Figure 5 and the pulse launched energy is $4.4 \mathrm{~J}$.

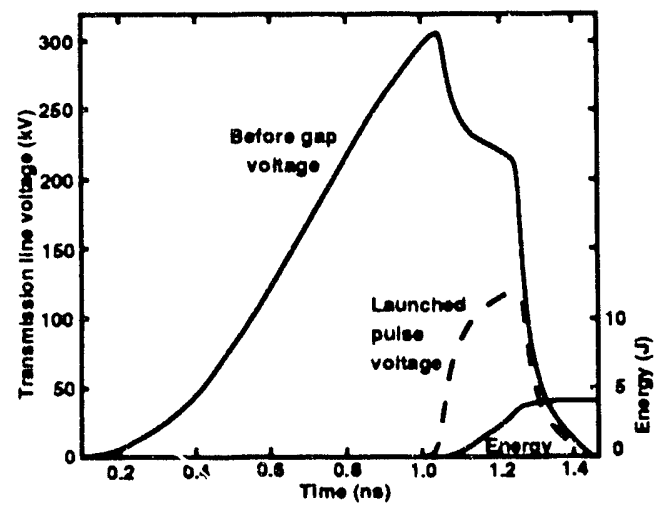

Figure 5. Calculated voltage pulses.

\section{Pulse Generator}

In early 1990 a FEBETRON flash $x$-ray machine was modified and used as an electrical pulse generator ${ }^{8}$. The wide band assist pulser (WASP), as it is now called, was improved in two areas to extend it's performance beyond the original design. First, changes were made to reduce the prepulse on the output associated with the charging of the Blumlein, and second undervoltage techniques were us ${ }^{\circ}$ to increase the repetition rate of the pulse generator from $100 \mathrm{~Hz}$ to $1 \mathrm{kHz}$.

A cross section view of the WASP pulse generator is shown in Figure 6. Three main sections make up the pulser; the Marx, the Blumlein, and the output switch chamber. Six A.L.E. 10 $\mathrm{kV}, 3 \mathrm{~kJ} / \mathrm{s}$ switching power supplies charge the Marx to $10 \mathrm{kV}$ in approximately $850 \mu$ s. Once the Marx has been charged, it is triggered with a $-17.5 \mathrm{kV}$ pulse and erects. Once erected, the Marx breaks down the master switch and charges the Blumlein. When the Blumlein reaches cliarge voltage, the multi-channel output switch self-breaks and the output pulse is launched down the Blumlein towards the load.

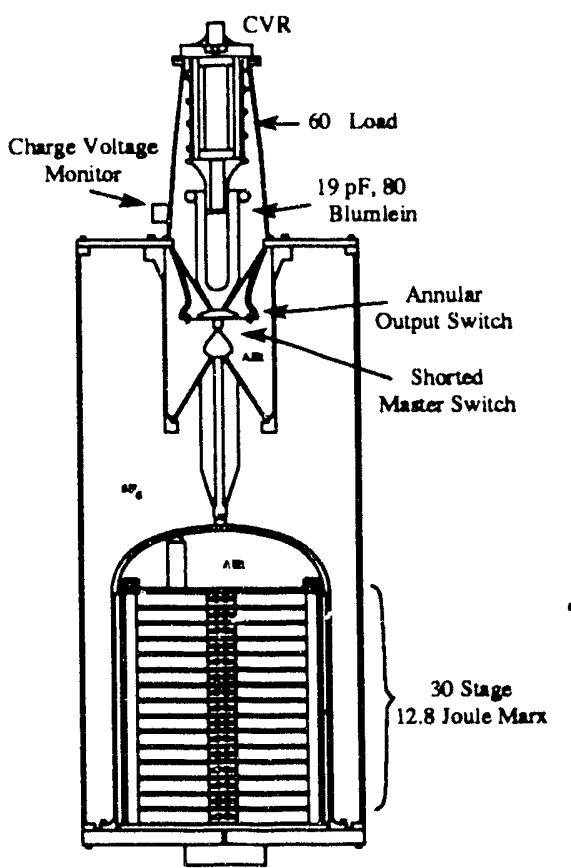

Figure 6. Cross section of WASP.

\section{Increase in repetition rate}

The overall work to increase the repetition rate of the system was broken into two tasks. First the rep-rate of the Marx was increased and second, the output section containing the Blumlein was modified. It has been shown that recovery times of the switches can be reduced an order-of-magnitude by undervolting the spark gaps by approximately $50 \% 9,10$. The pressure and gap spacing of the Marx spark gaps were undervolted. The Marx is triggered with a UV trigatron spark gap on the first stage of the Marx. New operating pressures and gap spacings were calculated and set on the Marx to provide for the necessary undervolting from the familiar Paschen relationship 9,10 .

$$
\mathrm{E}_{\max }=\frac{\mathrm{V}_{\max }}{x}=9.33\left(\frac{p}{T}\right)+3.77 \sqrt{\frac{p}{x T}}
$$

Here $\boldsymbol{x}$ is the gap separation in $\mathrm{cm}, \boldsymbol{p}$ is the pressure in Torr, and $T$ is the temperature in ${ }^{\circ} \mathrm{K}$. Due to the short charging time on the output switches, the voltage hold-off was approximately twice the calculated DC value ${ }^{13,14}$. Overall, the Marx was found to operate very repeatably to approximately 2 $\mathrm{kHz}$ for short bursts. 


\section{Spark Gap Recovery}

Voltage recovery was measured on the output switch for several repetition rates. A plot of the 2-pulse data is shown in Figure 7. As expected, since there are no initializing electrons in the spark gap to initiate the avalanche process, the switch is overvolted on the first pulse. This data matches data that has been recorded by others ${ }^{15}$. There is little dependency between the energy that is switched and the recovery time of the spark gap.

During the development and testing of the pulse generator, a total of 200,000 shots were put on the Marx and output switches before maintenance. Light puddeling on the electrodes was present, but no extensive erosion occurred. The long life of the switches is due to the low coulomb transfer of only $170 \mu \mathrm{C}$ (calculated for $0 \%$ reversal) ${ }^{16}$. The output switch, which has

- inconel electrodes was very nearly in perfect condition, after $2(00,000$ shots.

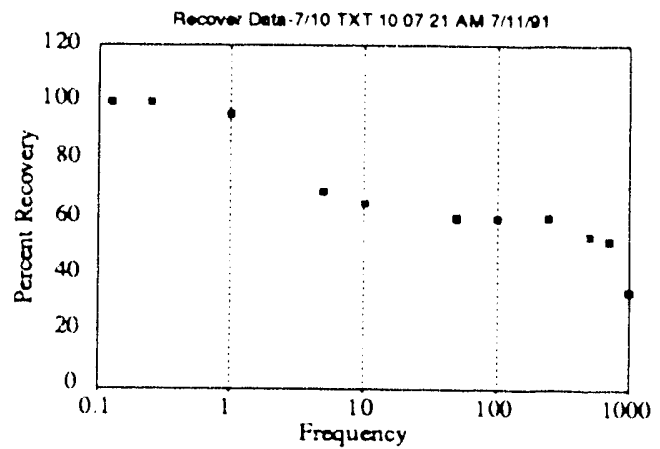

Figure 7. Output switch recovery.

\section{Senclusion}

The high-pressure switch has been shown to be capable of producing sub-nanosecond pulses at high voltages. Electric ficlds of a $\mathrm{few} \mathrm{MV} / \mathrm{cm}$ are attainable in charging pulses whose duration are of the order of the formative times for electron avalanching. The pulse rise times have been measured as fast as 150 ps (limited by diagnostics) and the pulse can be launched in phase along the gap, provided that a UV source of photons produces seed electrons before the charging pulse arrives. We have demonstrated that a $1-\mathrm{kHz}$ repetition rate can be achieved for this switch during a period of one second. Modeling has been effective in matching experimental results, and should thus be useful in the design of high-voltage and pressure switch configurations.

\section{Acknowledgments}

The authors of this paper would like to thank Dan Greenwood and Mario Fillipucci for their help on this project. We would also like to thank Ken Leighton, Bob Simpson, Sven Bredon, and Mike Brooks for their excellent technical support.

11] W. R. Cravey, Performance of a $30 \mathrm{kV}, I \mathrm{kH} / \mathrm{z}$ Nanosecond Source, IEEE, Proceedings of the 1992 Power Modulator Symposium, 1992. Gases, Stanford Lincar Accelerator, SLAC-PUB-4858, Feb. 1989: 4th Workshop: Pulsed Power Techniques for Future Accelerators, Eric, Trapini Italy, March 4-9, 1988.

[4] D. J. Mayhall and J. H. Yee, Computational broadband high-power electromagnetic pulse generation from an air gas avalanche switch, IEEE, Proceedings of the 1991 Pulsed Power Conference, 1991.

15] P. A. Pincosy, P. Poulsen, and W. R. Cravey, HighPressure Gas Switch for a Wideband Source, Beams 92, (th International Conference on High Power Particle Beams, Washington, D.C., May 25-29, 1992

[6] Cravey, W. R., P. Poulsen, and P. Pincosy, A Picosecond High Pressure Gas Swictch. Proccedings of IEEE 1990 Power Modulator Conference., 1990.

R. Babcock, I. Liberman, and W. Parlow, Volume Ultraviolet Preionizations Bare Sparks, IEEE J. Quant. Electron, vol. QE-12, p. 29, 1976.

Cravey, W. R., Freytag, E. K., and Leighton, K. S., A $150 \mathrm{kV}, 2.5 \mathrm{~ns}, 100 \mathrm{~Hz}$ Blumlein Pulser., Proceedings of IEEE 1990 Power Modulator Conference., 1990.

Moran, S. L., Grothaus, M. G., et al, Ilydrogen Spark Switches for Rep-Rated Accelerators, Proccedings of the 1992 Beams Conference, Washington D. C., 1992.

Moran, S. L., Haardesty, L. W., High-Repetition-Rate Hydrogen Spark Gap., Proceedings of IEEE 1990 Power Modulator Conference., 1990.

Hopkins, D. B., Design Considerations and data for Gas-Insulated High Voltage Structures,

Alswon, L. L., High Voltage Technology, Oxford University Press, New York, 1968.

Smith, I., Short-Pulse insulation and breakdown: a Phenomenological Review, Ian Smith Incorporated, 1979.

Martin, J. C., Nanosecond Pulse Techniques Circuit and Electromagnetic System Design, Note 4, April 1970, original SSWA/JCM/704/49.

Moran, S. L., Hairfield, S., High Pressure Spark Gap Recovery after Overvolted Breakdown., Proceedings of IEEE 5th Pulsed Power Conference., 1985.

Burkes, T. R., et al,, A critical Analysis and assessment of High Power Switches:, Report to Naval Surface Weapons Center, Dahlgren, Virginia., 1987.

* Work performed under the auspices of the U.S. Department of Energy by Lawrence Livermore National Laboratory under Contract No. W-7405-Eng-48. 

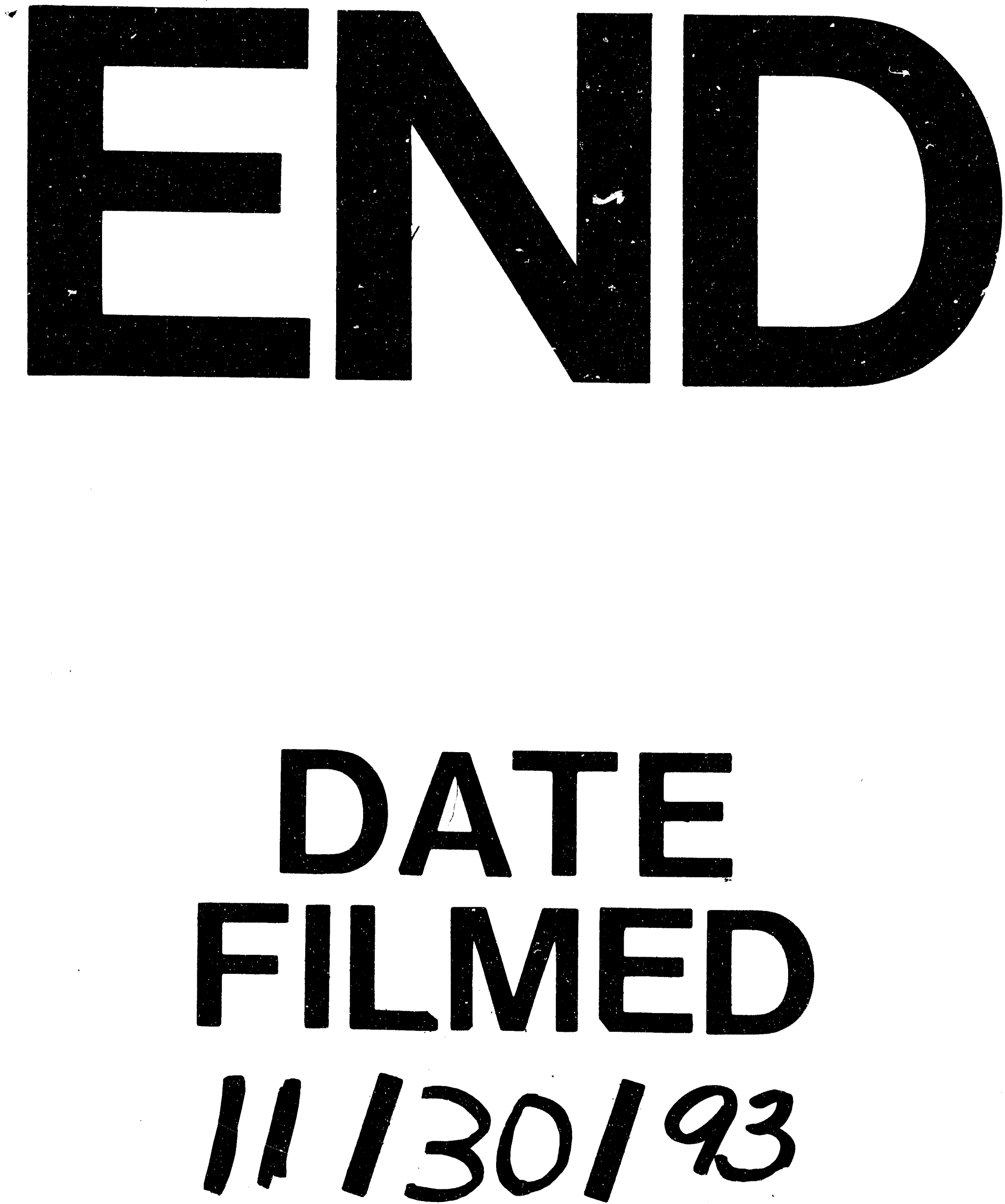
